\title{
Alpine thaw breaks ice over permafrost's role
}

Quirin Schiermeier, Munich

As Europe swelters in one of its hottest summers since records began, the heat is making itself felt in the high Alps, where thawing ice is destabilizing landscapes that are normally frozen.

Researchers who study permafrost say that the patterns of disruption being seen in the Alps right now could soon be replicated on a larger scale, with global warming eroding the quarter of the Earth's land surface that is permanently frozen.

In the Alps, most ground above an altitude of 2,500 metres - including about 6\% of Switzerland - remains frozen throughout the year, with only a surface layer less than 5 metres thick melting in the summer and re-freezing in winter. Above 3,000 metres, temperatures rarely exceed $0{ }^{\circ} \mathrm{C}$ for any length of time during the summer. In the past few weeks, however, ice has been thawing out steadily at altitudes of up to 4,600 metres.

Slopes containing ice-filled cracks and discontinuities have become unstable, rendering the area unsafe for climbers. On 15 July, for example, nearly 100 people were taken off the Matterhorn - Switzerland's best-known peak - by helicopter, after a rockslide had blocked their descent. At least 50 climbers have been killed this summer by Alpine rockfalls.

"Unfortunately, it is only incidents such as that at the Matterhorn that seem to raise awareness of the importance of permafrost research,” says Daniel Vonder Mühll,

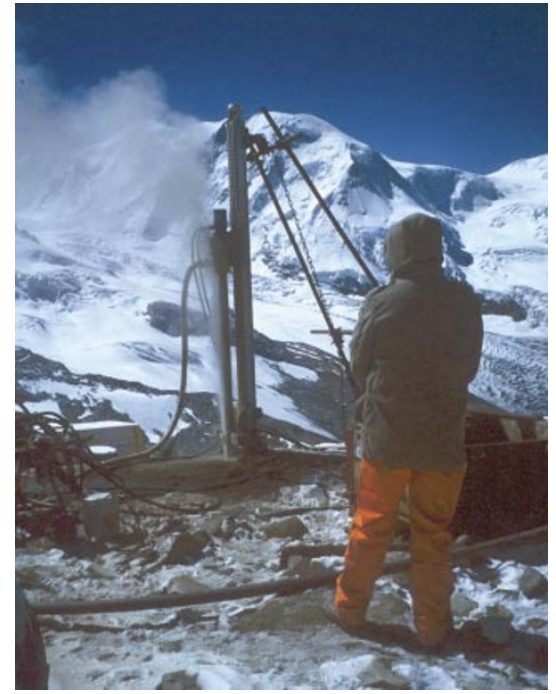

Digging deep: Swiss permafrost probes could provide clues to long-term climate change.

a geophysicist at the University of Basel in Switzerland.

Marcia Phillips, a geographer at the Swiss Federal Institute for Snow and Avalanche Research in Davos, investigates long-term permafrost changes in Switzerland, their impact on slope failure, and the stability of structures designed to hold back avalanches in Alpine valleys.

The institute is involved in PERMOS, a scheme to monitor permafrost temperature and slope stability at 26 drilling sites throughout the Swiss Alps. "There is a large variability, due to differences in topography. But by and large the threat of slope failure is increasing," says Phillips.

Permafrost thawing is not restricted to the Alps. In northern Europe and Russia, for example, thawing permafrost is a growing challenge to the construction and operation of roads, bridges and oil and gas pipelines.

Climatologists see permafrost as a sensitive lead indicator of climate change. Researchers in the European Union-funded Permafrost And Climate in Europe (PACE) project have found evidence of temperature increases of between 0.5 and $2.0{ }^{\circ} \mathrm{C}$ over the past $60-80$ years in permafrost soils in European mountain regions, from the Sierra Nevada in Spain to the arctic archipelago of Spitsbergen (C. Harris (ed.) Permafrost and Periglacial Processes 12 (1);2001).

"There is clear evidence for accelerated thawing in the upper permafrost layer in many regions," says Lorenz King, a geographer at Justus Liebig University in Giessen, Germany. If heavy snow in the winter insulates the ground from low air temperatures, permafrost can thaw even more deeply in summer, says Phillips.

Scientists have also suggested that permafrost melting can release vast amounts of carbon into the atmosphere, as the organic material that it contains is broken down by bacteria (see Nature 409, 751; 2001). This raises the spectre of a vicious circle in which these increasing quantities of greenhouse gases drive climate change, melting more permafrost and accelerating global warming.

\section{Flowers' sick trick gives botanists double trouble}

\section{John Whitfield, London}

Sickly plants have fooled botanists into incorporating the symptoms of their ailments into species descriptions, researchers say. The discovery raises the prospect that some plants currently classified as separate species are really just unhealthy samples of other groups.

"We need to continually validate the accuracy of species descriptions," says botanist Michael Hood of the University of Virginia, Charlottesville, co-author of a paper published last week that points out the error.

Hood and his colleague Janis Antonovics use herbarium specimens to map the distribution of plant diseases. As part of their study, they examined specimens of the genera Silene and Lychnis (which belong to the same family as carnations) in the herbarium of the National Museum of Natural History in Paris. The plants were collected in China about a century ago.
Of the 300 species examined, specimens of 25 were found to be infected with a fungus called anther smut. This causes the plant's anthers - the male sex organs - to become filled with dark purple spores instead of yellow pollen. None of the specimens had been noted as unusual by their collectors (M. E. Hood and J. Antonovics Proc. R. Soc. Lond. B (suppl.) doi: 10.1098/rsbl.2003.0063; 2003).

The diseased plants included the 'type specimens' for four species. A type specimen is the one on which a species' scientific description is based. Silene cardiopetala, for example, is distinguished from Silene tatarinowii by its dark anthers. Hood suspects that the plants may be one and the same. A flora of China published in 2001 repeats this description of $S$. cardiopetala.

"It's a cautionary tale," says Nicholas Turland, a specialist in Chinese plants at the Missouri Botanical Garden, St Louis. "It shows that when you describe a new species, you should collect lots of material, and not base it on a few specimens." Rare mutations could also produce errors, he points out.

Hood and Antonovics have so far failed to find similar mistakes in other plant groups. "How often this occurs is difficult to say," Hood says. "Either taxonomists are very good at distinguishing diseased specimens, or they are still hidden out there."

The disease discovery throws fresh light on a major problem area in taxonomy, botanists say. Bogus species names often arise when a researcher redescribes something that has already been named, or when different variants of a species such as flower colour - are given separate names. The International Plant Names Index contains more than one million entries, but researchers think that there are really only between 200,000 and 400,000 species of flowering plant. 